\title{
THE OCTOBER MEETING IN BALTIMORE
}

The six hundred fifty-ninth meeting of the American Mathematical Society was held at the Johns Hopkins University in Baltimore, Maryland, on Saturday, October 26, 1968. About 79 persons attended the meeting.

By invitation of the Committee to Select Hour Speakers for Eastern Sectional Meetings, there were two invited addresses. Professor Wilhelm Magnus of New York University spoke on Residually finite groups; he was introduced by Professor Jun-Ichi Igusa. Professor Avron Douglis of the University of Maryland spoke on The existence of weak solutions of first order partial differential equations; he was introduced by Professor Philip Hartman.

There were three sessions for sixteen contributed papers, chaired by Professors W. Schneider, D. E. Spencer and R. A. Struble.

HERBERT FedERER

Providence, Rhode Island 